\title{
Dietary patterns and their associations with demographic, lifestyle and health variables in a random sample of British adults
}

\author{
BY MARGARET J. WHICHELOW* \\ Department of Community Medicine, Institute of Public Health, University Forvie Site, \\ Robinson Way, Cambridge CB2 2SR \\ AND A. TOBY PREVOST \\ Centre for Survey Data Analysis, Department of Social Statistics, The University, \\ Highfield, Southampton SO17 1DJ
}

(Received 23 May 1995 - Revised 13 October 1995 - Accepted 15 November 1995)

\begin{abstract}
The present study aimed to identify dietary patterns, from the frequency of consumption of food items and some semi-quantitative data, in a random sample of 9003 British adults, and to examine the associations of the main dietary patterns with demographic factors, lifestyle habits, measures of selfreported health and mortality. Principal component analysis was used to identify four main dietary patterns, and analysis of variance employed to examine the characteristics associated with them. The four components explained, respectively, 10.2, 7.3, 5.1 and $4.9 \%$ of the total dietary variation. Component 1 , frequent fruit, salad and vegetable consumption with infrequent consumption of high-fat foods, was associated with middle age, non-manual socio-economic groups, non- and ex-smokers, 'sensible' drinkers, small households, the south of the country, and self-assessed 'excellent' or 'good' health. Component 2, frequent consumption of high-starch foods, most vegetables and meat, was popular with young men, older men and women, large households, non-smokers, non-drinkers and those who viewed themselves as healthy. Component 3 , frequent consumption of high-fat foods, was predominantly consumed by young people, smoking women, 'high-risk' drinkers, and men reporting many illness and/or malaise symptoms. Component 4 , high positive loadings for sweets, biscuits and cakes, with negative weightings for vegetables, was most favoured by students, the elderly, those living alone, residents in Scotland, but not those in central England, and those who did not smoke. For women only the first component was associated with low all-cause mortality, and the third component with excess mortality.
\end{abstract}

Dietary patterns: Lifestyle: Health

Previous studies on the Health and Lifestyle Survey data (Cox et al. 1987) have shown regional differences in eating patterns of many foods (Whichelow et al. 1991 a), distinct differences between the diets of smokers and non-smokers (Whichelow et al. 1991 b) and associations of the frequent consumption of certain foods, mainly fruit, with aspects of good health (Whichelow \& Treasure, 1990; Strachan et al. 1991). However, individual food items are not eaten in isolation and it is the whole diet which is important in the nourishment of the human being. Unhealthy eating has been related to lifestyle behaviour and occupational status in a study in Scotland (Abel \& McQueen, 1994). Other workers in the United Kingdom (Barker et al. 1990; Gregory et al. 1990), using weighed intakes of foods, have employed principal component analysis to identify important components of the diet and ANOVA to describe the style characteristics of subjects favouring them. Both

* Correspondence to be sent to Margaret J. Whichelow. 
studies showed distinct characteristics of the subjects following each of the dietary components with, notably, the healthiest diets being more likely to be consumed by nonmanual subjects and less likely to be chosen by smokers.

This approach has been adopted for the 9003 respondents in the 1984-5 Health and Lifestyle Survey (Cox et al. 1987), to relate diet type to demographic, lifestyle and health characteristics and, using logistic regression, mortality in the succeeding 7 years.

\section{METHODS}

The sampling procedures and execution of the first Health and Lifestyle Survey which took place in 1984-5 are described in detail elsewhere (Blaxter, 1987). From households selected at random in 198 representative constituencies in England, Scotland and Wales, 9003 adults (a response rate of $77.5 \%$ ) were interviewed. The age structure of the samples for both men and women compared well with that of the 1981 census. An interviewer visited the respondent at home and administered a questionnaire, which took approximately $1 \mathrm{~h} \mathrm{to}$ complete, covering attitudes to, and knowledge about, health, self-reported health, eating habits, smoking, alcohol consumption and exercise activities, as well as demographic details. For a wide variety of food items the frequency of consumption was recorded, in six categories (Whichelow, 1987). For seasonal foods such as fresh fruit and salad vegetables the respondents were asked about their consumption in summer and winter. For vegetables the questions posed were: 'Root vegetables, like carrots, turnips and parsnips', 'Peas and beans: all kinds, including baked beans and lentils', and 'Other cooked vegetables including onions and mushrooms'. The question about confectionery was asked as 'Sweets, chocolate' and for preserves as 'Jam, marmalade, golden syrup, honey'. Puddings were specified as 'Sweets or puddings, fruit pies, flans and tarts' and light desserts as 'Ice-cream, yoghurt, mousse, milk puddings'. Carcass meat was listed as 'Beef, lamb, pork, ham, bacon' and processed meat as 'Sausages, tinned meat, pâté, meat pies, pasties etc.'. The type of bread usually consumed was recorded and grouped as 'brown' which included all non-white breads, and 'white'. The types of milk (skimmed and semi-skimmed or full cream) and spread (low-fat or full-fat) were recorded, as was the average daily amount of bread consumed, in slices, and milk, in pints.

The respondents were divided by age into ten bands : $18-24,25-31,32-38,39-45,46-52$, $53-59,60-66,67-73,74-80$, and $81+$ years. This 7-year grouping was used for later comparison with the Health and Lifestyle Survey Follow-Up 1991-2 (Cox et al. 1993) carried out 7 years after the first.

Seven categories of head-of-household socio-economic group, namely professional, managerial, clerical etc., skilled manual, semi-skilled, unskilled and students, were identified. Members of the armed forces, and others, who had never been employed, were excluded.

The respondents were grouped into lifetime non-smokers, recent ex-smokers (regular smokers who had given up within the previous 7 years), long-term ex-smokers (regular smokers who had given up more than 7 years ago), current light smokers (1-15 cigarettes/d) and current heavy smokers (16 or more cigarettes/d). Current occasional smokers and those (men) smoking only pipes and cigars were excluded from the analysis.

The standard regions of Great Britain, i.e. Scotland, Wales, North, North West, Yorkshire/Humberside, West Midlands, East Midlands, East Anglia, South West, South East and Greater London were used.

Various measures for assessing health were employed in the survey. Respondents were asked whether, for their age, they considered their health to be 'excellent', 'good', 'fair' or 'poor'. The number of physical symptoms, of a list of sixteen, suffered in the previous 
month were recorded: 'illness' symptoms categorized into low (0-1 symptoms), average (2-3 symptoms), or high (4+ symptoms). Psychosocial 'malaise' symptoms, i.e. difficulty sleeping, 'nerves', difficulty concentrating, always feeling tired, worrying over every little thing, feeling under strain, feeling bored and feeling lonely, were similarly categorized. Details of longstanding or disabling disease conditions, including the severity of handicap, were also documented. Whether or not the respondent took vitamin pills or tonics was recorded, as was being on a 'diet' for medical reasons and the type of diet prescribed.

Drinking patterns were based on alcohol consumption in the previous week, with the categories being 'lifetime non-drinkers', 'nil last week' (which included many ex-drinkers), and as recommended by the Royal Colleges of Physicians, Psychiatrists and General Practitioners' report (1995), 'sensible drinkers' (1-21 units, men and 1-14 units, women), 'unwise drinkers' (22-50 units, men and 15-35 units, women) and 'high risk' (> 50 units, men and $>35$ units, women). As there were few 'high risk' female drinkers they were grouped with the 'unwise' drinkers.

The Survey respondents were 'flagged' with the National Health Service Register at the Office of Population Censuses and Surveys (OPCS), so that dates and causes of death of respondents are notified to the Health and Lifestyle Survey team as they occur.

\section{Statistical methods}

This paper sets out to assess potential associations between respondents' characteristics and thirty-nine food items. The food-frequency categories were translated numerically, i.e. 'more than once a day' 10 , 'daily' 7 , 'most days' 4.5 , 'once or twice a week' $1 \cdot 5$, 'less than once a week' 0.5 , and 'never' 0 .

Principal component analysis, using SPSSX (1990), was used to reduce the thirty-nine food items, which were standardized to ensure comparable variability to uncorrelated dietary components. Each dietary component is a weighted average of the food frequencies identified so that as much dietary variation as possible is retained in the components selected. Cattell's (1966) scree plot in conjunction with a $\chi^{2}$ test of isotropic variation (Mardia et al. 1979) was used to identify how many dietary components should be retained.

The weights that define a component are referred to as 'factor loadings' and have a useful interpretation as the actual correlations of food items with the component. A respondent's factor score on a component was calculated by multiplying the component's factor loadings by the respondent's standardized frequency of food consumption added up over each food item. ANOVA using GLIM (Payne, 1985) was employed to identify associations of subjects' characteristics with dietary components. The significance of characteristics was assessed using the $F$ distributed likelihood ratio test at the 5,1 and $0 \cdot 1 \%$ levels. Logistic regression analysis of the subsequent mortality status was carried out as survey subjects were flagged with OPCS (3616 men and 4767 women). Odds ratios (OR) were used to assess the risk of dying and the $\chi^{2}$ likelihood ratio test was used at the same significance levels.

\section{RESULTS}

\section{Dietary components}

Fig. 1 shows the relative importance of the thirty-nine derived dietary components. The isotropy $\left(\chi^{2}\right)$ test indicated that components six and seven were not different $(P=0 \cdot 21)$, that components three and four were different $(P=0.042)$ and that the remainder of the top seven components were highly significantly different from their neighbours $(P<0.001)$. This suggested that either four or seven components should be retained. The first four were chosen because they were defined by at least eight food items with factor loadings above 


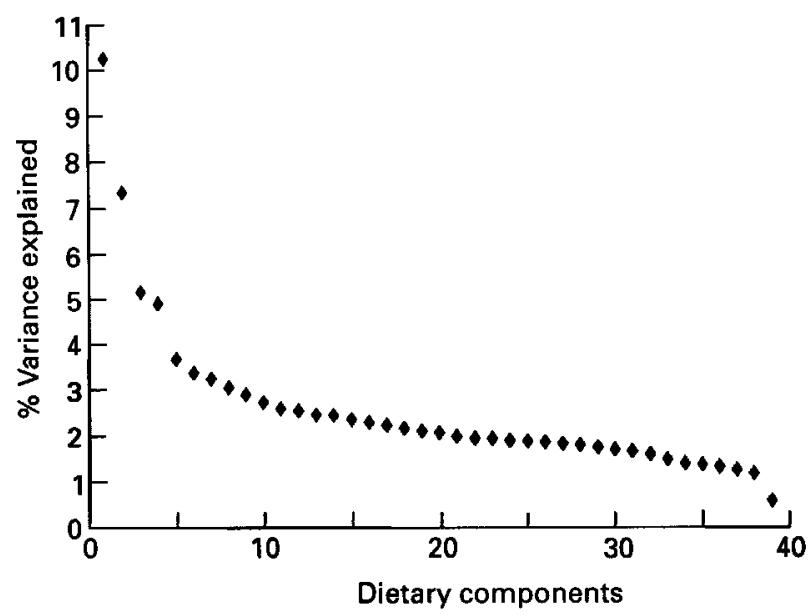

Fig. 1. Scree graph of percentage of dietary variance explained by the thirty-nine dietary components revealed by principal component analysis. Data from the Health and Lifestyle Survey (Cox et al. 1987).

$\pm 0 \cdot 3$, whereas the remaining components involved, at most, just four food items with loadings of \pm 0.3 or more, and were not judged to merit the title of 'dietary patterns'.

The derivation of the four dietary patterns was consistent over six data subsets defined by three age (18-38, 39-59, 60+ years) and two sex groups, with the same four components and very similar factor loadings appearing in each data subset.

The four principal components retained $27.5 \%$ of the variation in eating patterns (Table 1). Component 1 was strongly and positively associated with the frequent consumption of fresh foods (fruit and salads), high-fibre foods (fruit, vegetables and 'brown' bread) and low-fat spread and milk. It was negatively associated with many high-fat foods (chips, fried foods and processed meats).

Component 2 comprised mainly starchy foods as well as preserves, carcass meat and vegetables. Component 3 had strong positive loadings for high-fat foods, pasta and/or rice and coffee. Component 4 described essentially an eating pattern of very sweet food items in preference to all types of vegetables.

\section{Demographic characteristics}

Figs 2-5 show the unadjusted age trends for the four diets for non-manual and manual men and women. For both sexes component 1 was favoured more by those in middle age than the young or the very old. There were clear sex and socio-economic group differences at all ages. Component 2 was, for men, least popular in early middle age, whereas in women it was least favoured by the young and increased in popularity with age. At most ages the scores were higher in men than women and in manual than non-manual men. For component 3 the age pattern was very similar in men and women, and showed a steady decline with advancing age, from great popularity with the youngest groups, particularly the young men. Component 4 was most favoured by the young and the elderly and least popular with the middle-aged manual men. For all four diet components there were significant age associations $(P<0.001)$ for both sexes.

Table 2 shows the social and demographic characteristics associated with the four dietary components, each adjusted for all the other demographic, lifestyle and health factors. For both sexes component 1 was strongly and linearly associated with socio-economic status, being least often consumed by unskilled respondents and most popular with those in the 
Table 1. Factor loadings of thirty-nine foods in the four principal dietary components identified from the Health and Lifestyle Survey (Cox et al. 1987)

(Loadings greater than \pm 0.300 are given in italics)

\begin{tabular}{|c|c|c|c|c|}
\hline Dietary component... & 1 & 2 & 3 & 4 \\
\hline Variation explained (\%) & $10 \cdot 2$ & $7 \cdot 3$ & $5 \cdot 1$ & 4.9 \\
\hline Fruit (summer) & 0.648 & $0 \cdot 103$ & $0 \cdot 143$ & 0.234 \\
\hline Fruit (winter) & 0.650 & 0.097 & $0-070$ & $0 \cdot 202$ \\
\hline Cooked fruit & -0.070 & $0 \cdot 331$ & $0 \cdot 051$ & $0 \cdot 169$ \\
\hline Salad (summer) & 0.576 & 0.016 & $0 \cdot 234$ & -0.027 \\
\hline Salad (winter) & 0.565 & -0.014 & $0 \cdot 233$ & -0.034 \\
\hline Green vegetables & 0.441 & 0.314 & $-0 \cdot 013$ & -0.495 \\
\hline Root vegetables & $0 \cdot 353$ & $0 \cdot 346$ & -0.042 & -0.479 \\
\hline Pulses & 0.086 & 0.361 & 0.231 & -0.366 \\
\hline Other vegetables & $0 \cdot 354$ & 0.230 & $0-207$ & -0.356 \\
\hline Potatoes (excluding chips) & 0.036 & 0.460 & -0.288 & -0.308 \\
\hline Chips & -0.503 & 0.132 & $0 \cdot 416$ & $0 \cdot 001$ \\
\hline Crisps & -0.254 & $0 \cdot 136$ & 0.463 & $0 \cdot 190$ \\
\hline Nuts & 0.233 & 0.083 & $0 \cdot 200$ & 0.081 \\
\hline Confectionery & -0.142 & $0 \cdot 320$ & 0.098 & 0.405 \\
\hline Pasta/rice & 0.198 & 0.028 & $0 \cdot 321$ & 0.062 \\
\hline Breakfast cereal & 0.263 & 0.255 & $-0-173$ & 0.246 \\
\hline Biscuits & -0.096 & 0.422 & -0.124 & $0 \cdot 355$ \\
\hline Cake & -0.062 & 0.541 & $-0-253$ & $0 \cdot 323$ \\
\hline Puddings/pies & 0.013 & 0.559 & $-0 \cdot 174$ & $0 \cdot 208$ \\
\hline Light desserts & 0.251 & $0 \cdot 300$ & 0.011 & $0-242$ \\
\hline 'Brown' bread & 0.541 & $-0 \cdot 105$ & -0.096 & $0 \cdot 123$ \\
\hline Bread (amount) & -0.286 & 0.270 & 0.243 & -0.051 \\
\hline Sandwiches & $-0 \cdot 141$ & 0.094 & $0 \cdot 183$ & 0.019 \\
\hline Spread (low fat) & 0.387 & -0.182 & 0.052 & 0.096 \\
\hline Preserves & 0.161 & 0.368 & $-0 \cdot 301$ & $0 \cdot 188$ \\
\hline Milk (semi-skimmed/skimmed) & $0 \cdot 359$ & -0.225 & 0.058 & $0 \cdot 070$ \\
\hline Milk (amount) & $-0 \cdot 097$ & $0 \cdot 309$ & 0.082 & 0.049 \\
\hline Cream & 0.097 & $0 \cdot 333$ & 0.000 & $0 \cdot 118$ \\
\hline Cheese & $0 \cdot 185$ & 0.240 & $0 \cdot 138$ & $0-079$ \\
\hline Eggs & -0.079 & 0.303 & 0.221 & $-0 \cdot 190$ \\
\hline Fish & 0.208 & 0.082 & 0.079 & $-0 \cdot 139$ \\
\hline Poultry & $0 \cdot 196$ & 0.041 & 0.263 & -0.090 \\
\hline Carcass meat & $-0 \cdot 012$ & $0 \cdot 360$ & $-0 \cdot 086$ & -0.257 \\
\hline Processed meat & -0.359 & 0.223 & $0 \cdot 308$ & -0.045 \\
\hline Fried food & -0.411 & 0.229 & 0.358 & $-0 \cdot 122$ \\
\hline Soft drinks & $-0 \cdot 155$ & 0.111 & 0.419 & 0.194 \\
\hline Fruit juice & 0.477 & 0.013 & 0.173 & $0 \cdot 146$ \\
\hline Tea (no. of cups) & $-0 \cdot 167$ & 0.264 & -0.331 & 0.203 \\
\hline Coffee (no. of cups) & $0 \cdot 174$ & -0.152 & 0.321 & 0.093 \\
\hline
\end{tabular}

professional group. Amongst men, component 2 was associated with the manual groups and component 4 most often consumed by students, whilst manual men and professional women also achieved higher scores on component 4.

Household size was associated in different ways with the four components. Compared with a household size of two, the respondent and one other, components 1 and 4 were less likely to be consumed in large households. Component 1 was most popular with women, but not with men, living on their own. Component 2 increased in popularity with increasing household size, with those living alone unlikely to follow this pattern.

There were considerable regional variations associated with the dietary components. In 


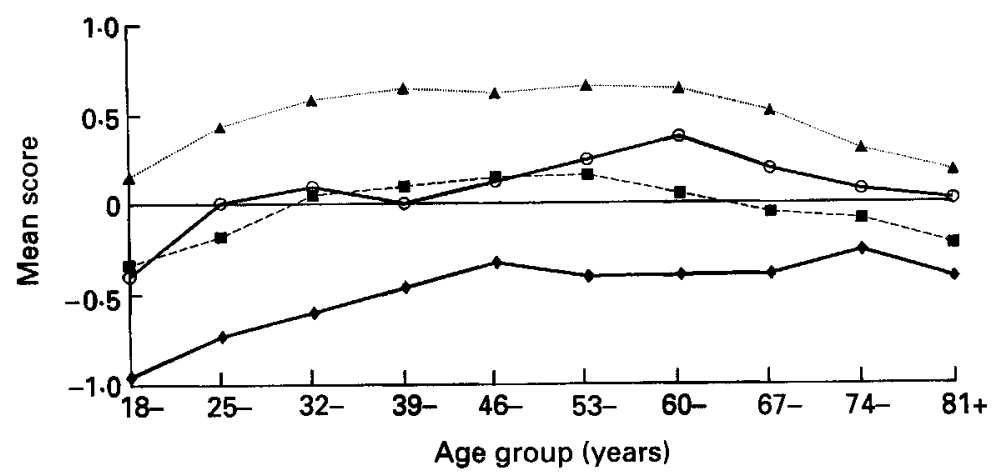

Fig. 2. Age trends in scores on dietary component 1, relative to total population mean score of zero. (A), Nonmanual women; $(\square)$, manual women; $(O)$, non-manual men; $(\bullet)$, manual men.

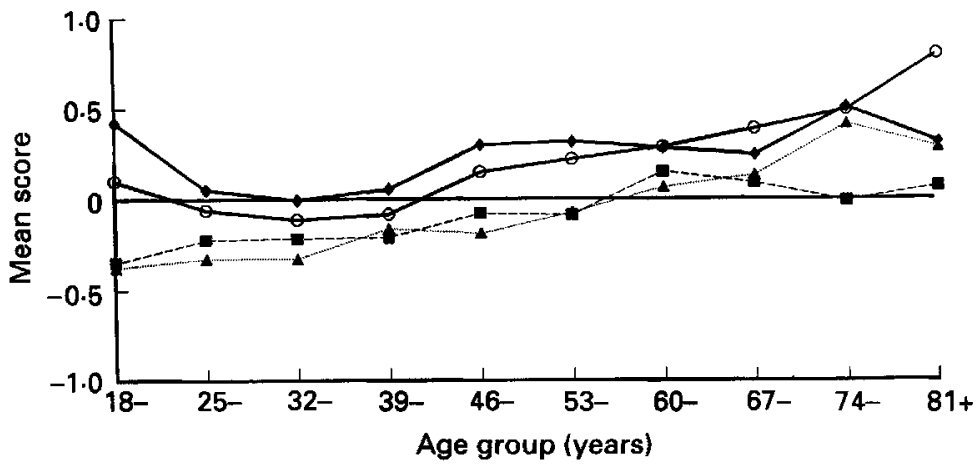

Fig. 3. Age trends in scores on dietary component 2, relative to total population mean score of zero. ( $\boldsymbol{A})$, Nonmanual women; (C), manual women; $(\mathrm{O})$, non-manual men; $(\diamond)$, manual men.

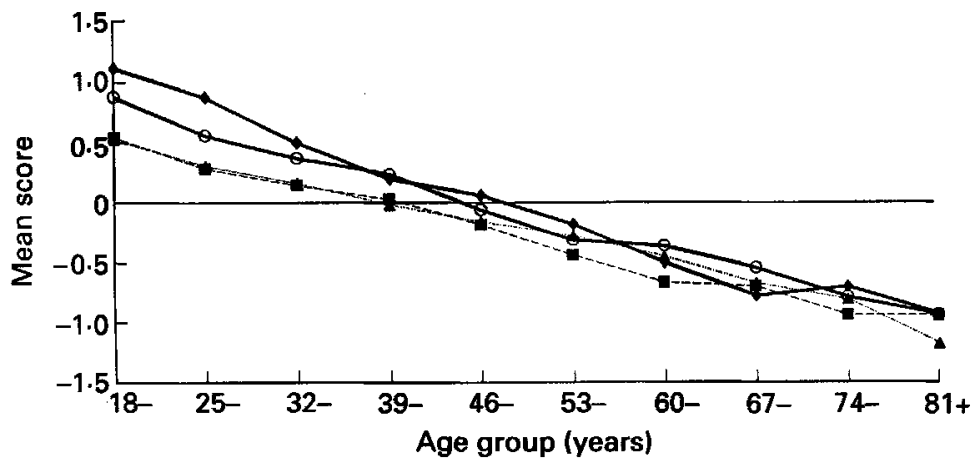

Fig. 4. Age trends in scores on dietary component 3, relative to total population mean score of zero. (A), Nonmanual women; $(\boldsymbol{Q})$, manual women; $(0)$, non-manual men; $(\bullet)$, manual men.

comparison with the South East, component 1 was significantly less likely to be consumed by men and women in most other regions, and there was a clear North-South gradient (Table 2). Component 2 was most popular amongst men in East Anglia and women in the East Midlands, the North and Wales, and least popular amongst men in Wales. The 


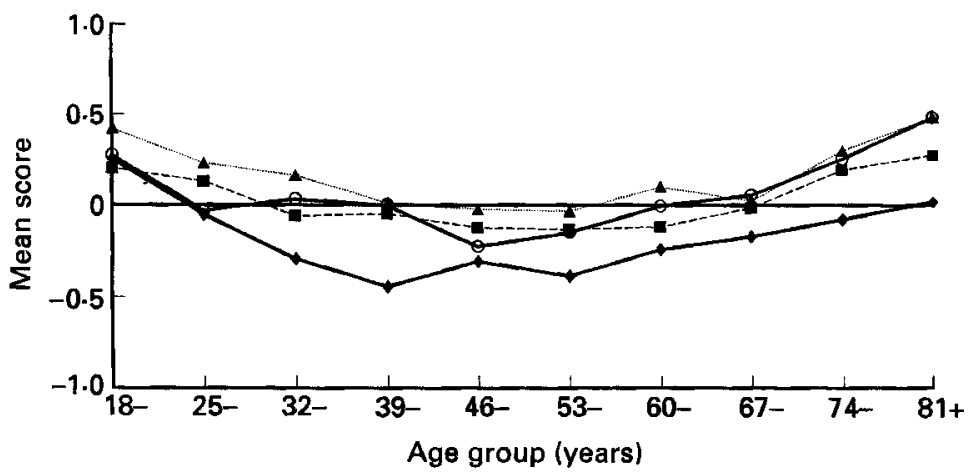

Fig. 5. Age trends in scores on dietary component 4, relative to total population mean score of zero. (A), Nonmanual women; (a), manual women; (O), non-manual men; $(\diamond)$, manual men.

popularity of component 3 varied little between the regions for either sex. Component 4 was most popular amongst Scottish respondents, and least favoured by those in Yorkshire/Humberside.

There were clear ethnic differences, with the non-white respondents more likely to consume components 1 and 3 and less likely to favour component 2 .

A high proportion of the variations in the characteristics of the components 1 and 3 consumers could be explained by demographic factors alone, in both sexes (see Table 5).

\section{Lifestyle factors}

After allowing for all other factors, Table 3 shows that there were strong associations with behavioural factors. Current smokers, and most markedly the heavy smokers, were significantly less inclined to components 1,2 and 4 whilst female current smokers were more inclined to component 3 than their non-smoking counterparts. In general ex-smokers, particularly those of long duration, had dietary patterns similar to those of lifetime nonsmokers.

In both sexes the 'sensible' drinkers had higher scores on component 1 than the other drinking groups. Amongst the men the 'high risk' drinkers (over 50 units per week) scored significantly lower on components 1,2 and 4 , but were the highest scoring group on component 3. The differences were not so marked for the women where the 'Nil last week' group, which included many ex-drinkers, scored lower on component 1, whereas the 'unwise/high risk' drinking group had a score similar to that of the sensible drinkers. The 'unwise/high risk' drinking women had the lowest scores on components 2 and 4 but the highest on component 3 .

Respondents who reported taking tonics or vitamin pills scored higher on component 1 and, for women, on component 4 , than those who did not take dietary supplements. Both men and women who reported following a prescribed diet favoured component 1 , as opposed to components 2 and 3 (men) or components 2 and 4 (women).

Having controlled for demographic factors, lifestyle factors accounted for less of the variation in each of the four dietary patterns than did demographic factors (see Table 5). For component 3 in particular, very little variation was explained by lifestyle habits.

\section{Health measures}

After adjusting for all the other factors considered, long-standing illness, whether it resulted in disability or not, was not related to any of the dietary components (Table 4). Experience of physical illness symptoms in the past month was related positively to component 2 and, 
M. J. WHICHELOW AND A. T. PREVOST

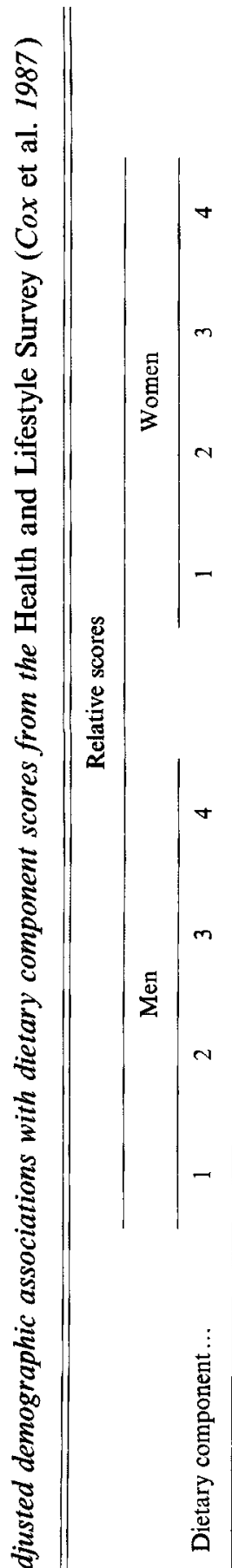

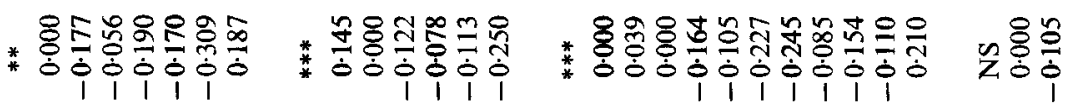

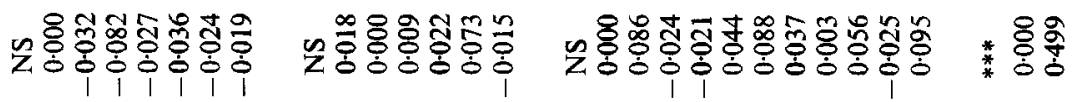

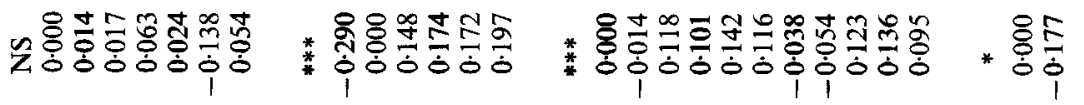

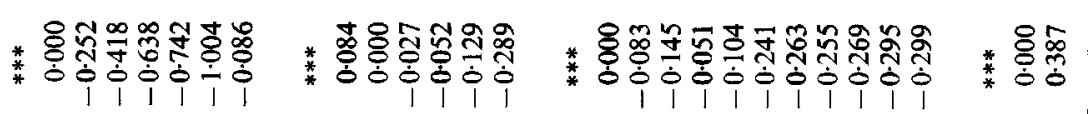

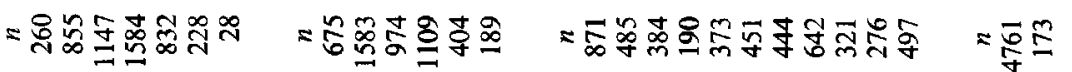

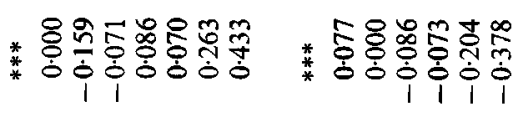

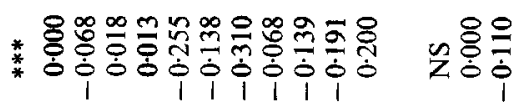

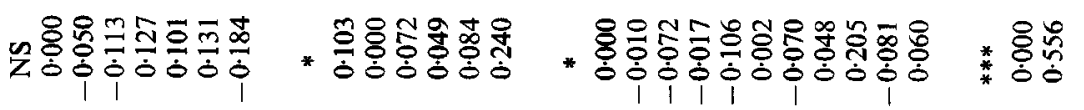

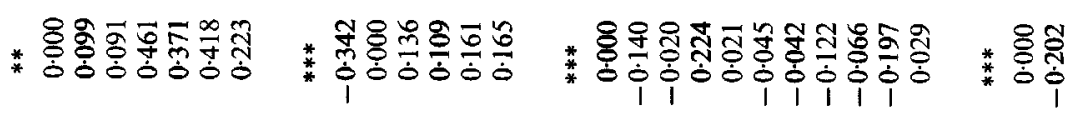

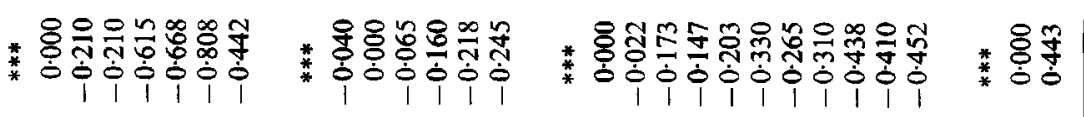

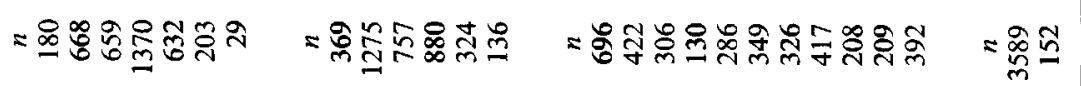

斗

. 
DIETARY PATTERNS IN BRITISH ADULTS

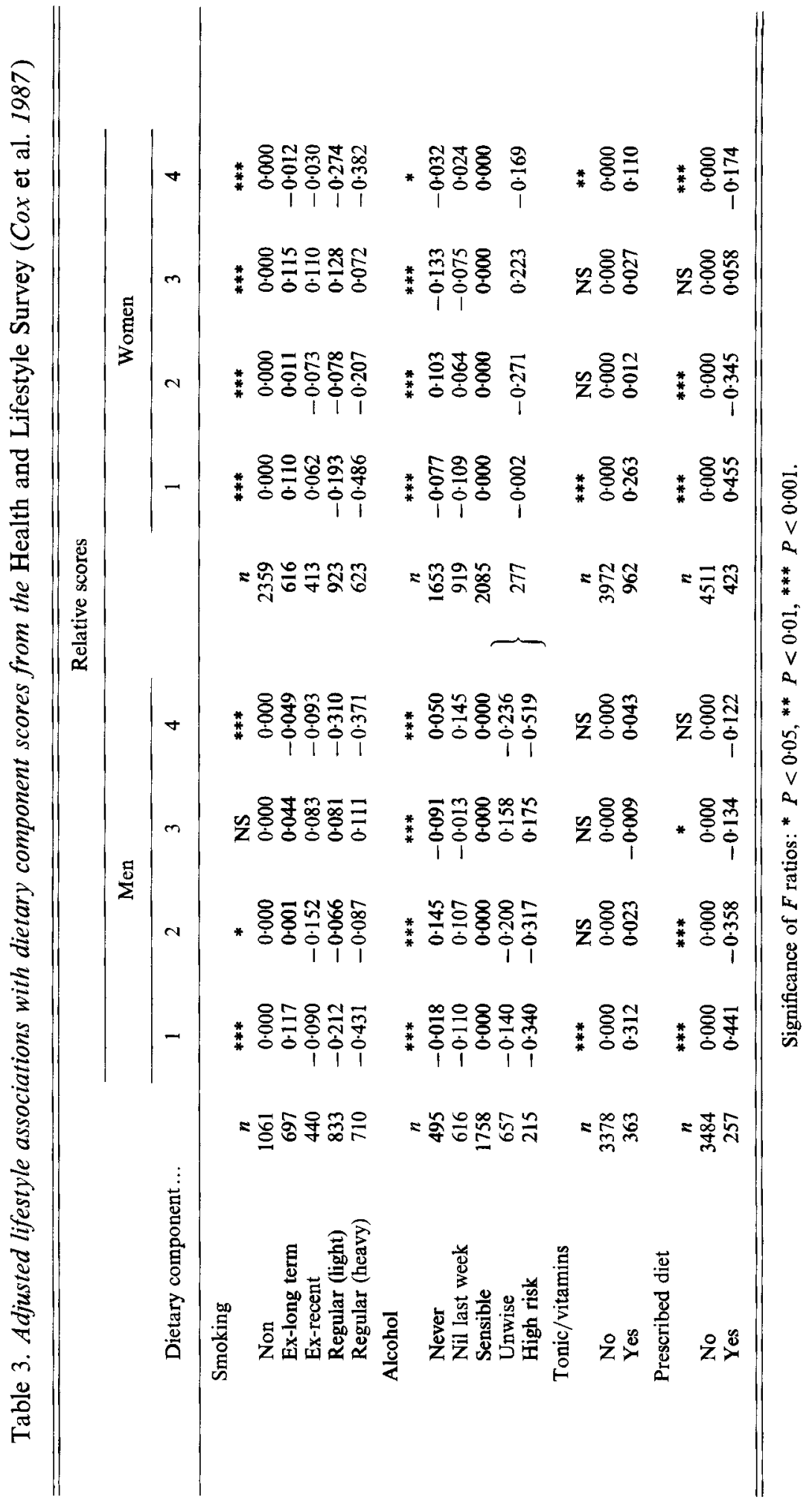


M. J. WHICHELOW AND A. T. PREVOST

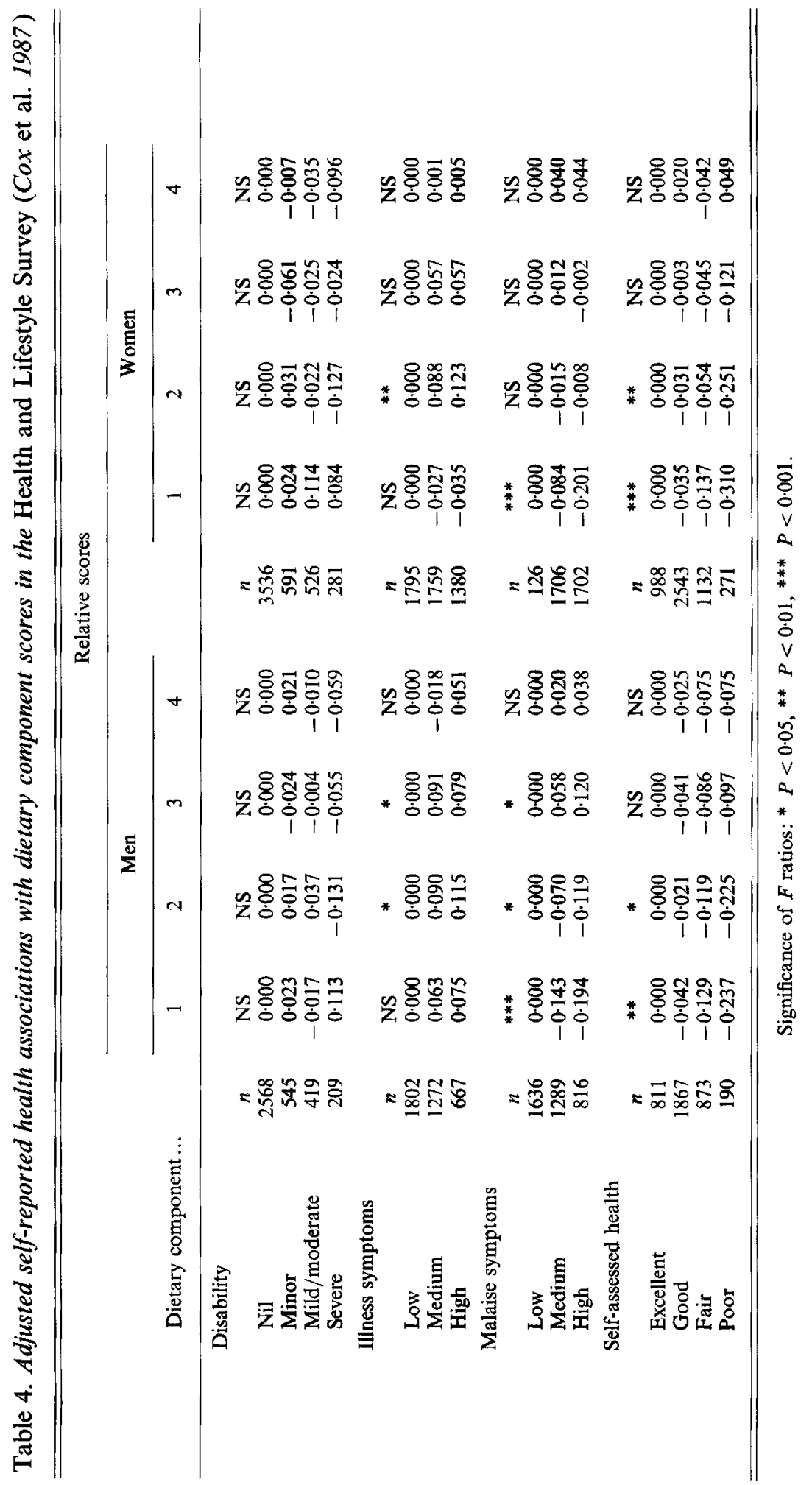


Table 5. Proportion of variation in each dietary component explained by characteristics studied

\begin{tabular}{|c|c|c|c|c|c|c|c|c|}
\hline \multirow[b]{2}{*}{ Dietary component... } & \multicolumn{4}{|c|}{ Men } & \multicolumn{4}{|c|}{ Women } \\
\hline & 1 & 2 & 3 & 4 & 1 & 2 & 3 & 4 \\
\hline $\begin{array}{l}\text { Demographic } \\
\text { Lifestyle } \\
\text { Self-reported health } \\
\text { Total }\end{array}$ & $\begin{array}{r}21 \cdot 0 \\
7 \cdot 9 \\
1 \cdot 1 \\
30 \cdot 0\end{array}$ & $\begin{array}{r}6 \cdot 5 \\
2 \cdot 8 \\
0 \cdot 8 \\
10 \cdot 1\end{array}$ & $\begin{array}{r}31.8 \\
0.9 \\
0.4 \\
33 \cdot 1\end{array}$ & $\begin{array}{r}7 \cdot 5 \\
5 \cdot 3 \\
0 \cdot 1 \\
12 \cdot 9\end{array}$ & $\begin{array}{r}15 \cdot 8 \\
6.8 \\
1 \cdot 6 \\
24 \cdot 2\end{array}$ & $\begin{array}{l}6 \cdot 5 \\
2 \cdot 4 \\
0 \cdot 6 \\
9 \cdot 5\end{array}$ & $\begin{array}{r}24 \cdot 3 \\
1 \cdot 4 \\
0.2 \\
25 \cdot 9\end{array}$ & $\begin{array}{l}5 \cdot 2 \\
2 \cdot 8 \\
0 \cdot 1 \\
8 \cdot 1\end{array}$ \\
\hline
\end{tabular}

in men only, to component 3. Malaise symptoms were closely and negatively associated with component 1 in men and women, and to a lesser extent in men with component 2 , whilst component 3 was associated in men with many malaise symptoms. Both components 1 and 2 showed a positive trend with self-assessed health.

Variations in self-reported health, after allowing for demographic and lifestyle factors, accounted for even less of the variations in each of the four diets than did demographic or lifestyle factors (Table 5). Overall a considerable proportion of the variation was explained by the three areas studied for components 1 and 3 , but much less for components 2 and 4 .

\section{Mortality}

By 1991-2, when the follow-up survey was undertaken, death notifications had been received for 387 men of the 3616 who were flagged, and 376 women of the 4767 flagged. Associations, after adjusting for all other factors, between mortality and diet were found only in women and only for component 3 . For each incremental unit on the score of component 1 the risk of dying decreased (OR $0.760(95 \% \mathrm{CI} 0.646,0.894) P<0.001)$ and for component 3 in women increased (OR $1.200(95 \% \mathrm{CI} 1.016,1.418) P=0.033)$.

\section{DISCUSSION}

In the Health and Lifestyle Survey (HALS), time constraints, the large number of subjects studied and the broad nature of the survey rendered it impossible to obtain more dietary information than could be gleaned by a food-frequency questionnaire. Nevertheless principal component analysis of the thirty-nine food items revealed four main dietary components, which accounted for $27.5 \%$ of the dietary variation, 2.7 times as much as the $10 \%$ expected. The OPCS survey (Gregory et al. 1990) using $7 \mathrm{~d}$ weighed intakes derived five components accounting for $22.6 \%$ of total variation in fifty-four food items, 2.4 times as much as the $9 \%$ expected, whereas Barker et al. (1990) who also used $7 \mathrm{~d}$ weighed intakes found that $21.5 \%$ of the total variation was accounted for by four components derived from forty-two food items, $2 \cdot 3$ times as much as the $9.5 \%$ expected.

Despite the different methods of data collection and although different numbers of foods were used in the analyses, the dietary patterns in the three surveys revealed many similarities. The first components in the HALS and OPCS surveys showed similar loadings for fruit, salads, brown bread and types of milk and spread and compared well with the second component in the Northern Ireland survey (Barker et al. 1990). HALS component 2 showed many similarities to the OPCS third component, and some foods with high factor loadings were prominent in the first component ('traditional' diet) in the Northern Ireland study. HALS component 3 shared high positive loadings for chips and processed meat products with the third Northern Ireland component and the second and fifth OPCS diets. 
A study in Switzerland (Gex-Fabry et al. 1988), using a dietary history, identified three main dietary components. The first component included high factor loadings for fruit, vegetables and fruit juice, which are similar to those in the first component in the present study. There were also similarities between their second component, a 'satiating' diet, and the HALS component 2. The findings all suggest that there are established dietary preferences: where certain foods are consumed, others will be too. Analysis by three age and the two sex groups, which all revealed the same four components with almost identical factor loadings for the food items in each component, suggested that these dietary preferences are robust for men and women across all ages.

The characteristics of respondents who had high scores on component 1 , where foods high in dietary fibre and antioxidant vitamins and low in fat are predominant, indicated a 'health conscious' attitude to life as they also tended to be non-smokers, 'sensible' drinkers and were more likely to adhere to medically prescribed diets and take food supplements. Other studies have also reported clustering of lifestyle habits (Anderson \& Hunt, 1992; Anderson et al. 1994). Since dietary advice for most common conditions, such as obesity, high blood pressure, diabetes and high serum cholesterol, is to reduce fat and simple carbohydrates and to increase dietary fibre, the associations should be encouraging for those involved in health promotion. Component 1 was associated with respondents who viewed their health as 'excellent' and who suffered few malaise symptoms. It is not possible to determine from this cross-sectional study whether the feeling of well being was a result of following the diet, or whether those who felt healthy were then more likely to choose the foods of this dietary pattern.

As with the first component in the OPCS study, this dietary pattern was associated with the non-manual groups, reflecting the socio-economic and also regional variations in consumption of many individual foods prominent in component 1 reported in other studies (Fehily et al. 1984, 1991; British Nutrition Foundation, 1985; Whichelow, 1987, 1989; Whichelow et al. 1991 a). The age trends suggested either that men and women in both nonmanual and manual groups become more conscious of choosing healthy foods as they approach middle age, or that a cultural change was occurring whereby the younger age groups were following different eating patterns from their parents. This is also an issue with component 3.

Many of the foods with high factor loadings in component 2 can be considered to be the constituents of a 'main' or 'traditional' meal of meat, potatoes and other vegetables, with a second course. Most items require preparation and cooking, which may account for it rarely being followed by respondents living alone, and its popularity with large households.

Those with high scores on component 3 , which has high factor loadings for many convenience and often high-fat foods, were mostly the younger respondents. Otherwise there were few demographic associations, in contrast to the other dietary components. This was the only component associated with drinking above the 'sensible' level and with current smoking, although the latter did not achieve significance in the men. Even when these poor lifestyle habits were adjusted for, the association, for men, with self-reported poor health and, for women, with mortality, suggests that this is the least desirable of the dietary components identified.

Component 4 showed no associations with any of the health measures, but it was nevertheless associated with some healthy lifestyle practices, namely non-smoking and nondrinking. It was most popular with students and those living on their own, possibly because the major items of the diet (biscuits, cakes and confectionery) require little preparation and are satiating. Cultural habits may account for its following in Scotland, where there is a lower consumption of many types of vegetables than in the rest of Great Britain (Whichelow et al. 1991a). 
Comparison of the present findings with those of other studies in respect of alcohol consumption is not possible, because in the Northern Ireland and OPCS studies alcohol, as grams consumed per day, was included as an item of diet in the principal component analysis. The findings described in the present paper of a $\mathrm{J}$-shaped association with component 1 suggest that the relationships between eating and drinking alcohol are complex.

The Health and Lifestyle Survey is unique amongst surveys in the British Isles in also examining measures of self-reported health in relation to dietary patterns. There was no association with the reporting of long-standing illness or disability, nor the severity of such, with any of the dietary components but the responses covered such a wide variety of conditions that some associations could have been masked. However, when current or very recent (within the past month) symptoms were considered some interesting relationships were revealed.

The findings on mortality, when all the other demographic, social, lifestyle and health measures are taken into account, indicate that a good diet is more important for longevity in women than men. A recent study on the Health and Lifestyle Survey data showed that, in contrast, after adjustment for social class and other factors, a low household income was a predictor of mortality for men but not for women (B. D. Cox, unpublished results).

Overall, the findings reported here show important patterns of dietary habits and their associations with not only lifestyle habits, but also measures of health and mortality, which should be of value to those involved in health promotion. These also provide the basis for examination of the relationship of the changes in diet, other lifestyle habits and health in the seven years between the Health and Lifestyle Survey and the follow up survey of the survivors in 1991-2 which will be reported shortly.

\section{REFERENCES}

Abel, T. \& McQueen, D. V. (1994). Determinants of selected unhealthy eating behaviours among male and female adults. European Journal of Public Health 4, 27-32.

Anderson, A. S. \& Hunt, K. (1992). Who are the 'healthy eaters'? Eating patterns and health promotion in the west of Scotland. Health Education Journal 51, 3-10.

Anderson, A. S., Macintyre, S. \& West, P. (1994). Dietary patterns among adolescents in the West of Scotland. British Journal of Nutrition 71, 111-122.

Barker, M. E., McClean, S. I., Thompson, K. A. \& Reid, N. G. (1990). Dietary behaviours and socio-cultural demographics in Northern Ireland. British Journal of Nutrition 64, 319-329.

Blaxter, M. (1987). Sample and data collection. In The Health and Lifestyle Survey, pp. 1-3. Cambridge: Health Promotion Research Trust.

British Nutrition Foundation (1985). Eating in the Early 1980s, p. 19. London: The British Nutrition Foundation. Cattell, R. B. (1966). The Scree test for the number of factors. Multivariate Behaviour Research 1, 245-276.

Cox, B. D., Blaxter, M., Buckle, A. L. J, Fenner, N. P., Golding, J. F., Gore, M., Huppert, F. A., Nickson, J., Roth, M., Stark, J., Wadsworth, M. E. J. \& Whichelow, M. J. (1987). The Health and Lifestyle Survey: A Preliminary Report of a Nationwide Survey of the Physical and Mental Health, Attitudes and Lifestyle of a Random Sample of 9003 British Adults. Cambridge: Health Promotion Research Trust.

Cox, B. D., Huppert, F. A. \& Whichelow, M. J. (1993). The Health and Lifestyle Survey: Seven Years On. Aldershot: Dartmouth Publishing Company.

Fehily, A. M., Phillips, K. M. \& Yarnell, J. W. G. (1984). Diet, smoking, social class and body mass index in the Caerphilly Heart Disease Study. American Journal of Clinical Nutrition 40, 827-833.

Fehily, A. M., Vaughan-Williams, E., Shiels, K., Williams, A. H., Horner, M., Bingham, G., Holliday, R. M., Sweetnam, P. M. \& Burr, M. L. (1991). Factors influencing compliance with dietary advice: the Diet and Reinfarction Trial (DART). Journal of Human Nutrition and Dietetics 4, 33-42.

Gex-Fabry, M., Raymond, L. \& Jeanneret, O. (1988). Multivariate analysis of dietary patterns in 939 Swiss adults: socio-demographic parameters and alcohol consumption profiles. International Journal of Epidemiology 17, $548-555$.

Gregory, J., Foster, K., Tyler, H. \& Wiseman, M. (1990). The Dietary and Nutritional Survey of British Adults. London: H.M. Stationery Office.

Mardia, K. V., Kent, J. T. \& Bibby, J. M. (1979). Multivariate Analysis, p. 236. London: Academic Press.

Payne, C. D. (1985). The GLIM System, Release 3.77. Oxford: Numerical Algorithms Group Ltd. 
Royal Colleges of Physicians, Psychiatrists and General Practitioners (1995). Alcohol and the Heart in Perspective: Sensible Limits Reaffirmed. London: Royal College of Physicians.

SPSSX (1990). SPSS Advanced Users Guide. Chicago: SPSS Inc.

Strachan, D. P., Cox, B. D., Erzinclioglu, S. W., Walters, D. E. \& Whichelow, M. J. (1991). Ventilatory function and winter fresh fruit consumption in a random sample of British adults. Thorax 46, 624-629.

Whichelow, M. J. (1987). Dietary habits. In The Health and Lifestyle Survey, pp. 67-84. Cambridge: Health Promotion Research Trust.

Whichelow, M. J. (1989). Choice of spread by a random sample of the British population. European Journal of Clinical Nutrition 43, 1-10.

Whichelow, M. J., Erzinclioglu, S. W. \& Cox, B. D. (1991 a). Some regional variations in dietary patterns in a random sample of British adults. European Journal of Clinical Nutrition 45, 253-262.

Whichelow, M. J., Erzinclioglu, S. W. \& Cox, B. D. (1991b). A comparison of the diets of non-smokers and smokers. British Journal of Addiction 86, 71-81.

Whichelow, M. J. \& Treasure, F. P. (1990). Diet and health in a random sample of British adults. Proceedings of the Nutrition Society 49, 57A Abstr. 